\title{
THE
}

1986

\section{On Gulf Stream meander characteristics near Cape Hatteras}

\author{
Karen L. Tracey \\ University of Rhode Island, krltracey@uri.edu \\ D. Randolph Watts \\ University of Rhode Island, randywatts@uri.edu
}

Follow this and additional works at: https://digitalcommons.uri.edu/gsofacpubs

Terms of Use

All rights reserved under copyright.

\section{Citation/Publisher Attribution}

Tracey, K. L., and D. R. Watts (1986), On Gulf Stream meander characteristics near Cape Hatteras, J. Geophys. Res., 91(C6), 7587-7602, doi: 10.1029/JC091iC06p07587

Available at: http://dx.doi.org/10.1029/JC091iC06p07587

This Article is brought to you for free and open access by the Graduate School of Oceanography at DigitalCommons@URI. It has been accepted for inclusion in Graduate School of Oceanography Faculty Publications by an authorized administrator of DigitalCommons@URI. For more information, please contact digitalcommons-group@uri.edu. 


\title{
On Gulf Stream Meander Characteristics Near Cape Hatteras
}

\author{
Karen L. TraceY and D. RandolPh Watts
}

Graduate School of Oceanography, University of Rhode Island, Narragansett

\begin{abstract}
From 1979 to 1982, Gulf Stream path fluctuations within $375 \mathrm{~km}$ downstream of Cape Hatteras, North Carolina, have been monitored by inverted echo sounders. Histograms of the north wall locations along four cross-stream sections change shape and increase in range dramatically downstream through the study area: Near Cape Hatteras, the histogram is peaked with the Gulf Stream found over half of the time within a narrow $10-\mathrm{km}$ range. The distributions become progressively more symmetric and the ranges widen downstream such that in the eastern portion of the study area the Gulf Stream can be found with equal probability throughout its $145-\mathrm{km}$ excursion range. From the 36-month-long time series near $73^{\circ} \mathrm{W}$ there is evidence of a seasonal cycle of Gulf Stream positions; northerly locations occur in the summer/fall, when transports are lower, and southerly locations occur in the winter/spring, when transports are higher. An observational dispersion relationship is presented for meander propagation and growth: Downstream propagation rates increase smoothly from about $14 \mathrm{~km} \mathrm{~d}^{-1}$ for meanders with periods and wavelengths $(33$ days, $460 \mathrm{~km})$ to over $45 \mathrm{~km} \mathrm{~d} \mathrm{~d}^{-1}$ for the $(4$ days, $180 \mathrm{~km})$ meanders. Meander amplitudes show rapid growth rates in two separate bands, near (4-5 days, 180-230 km) and (10-33 days, 300-500 km).
\end{abstract}

\section{INTRODUCTION}

The Gulf Stream exhibits time-dependent wavelike lateral displacements (meanders) along its entire path. The predominant wavelengths and propagation speeds change from south to north, however, particularly at Cape Hatteras where the Gulf Stream leaves the continental margin and flows into deeper water.

South of Cape Hatteras, the dominant meanders have periods of 3 and 7-8 days and wavelengths of $100-250 \mathrm{~km}$ [Brooks and Bane, 1981]. Their rms lateral amplitudes are 10-30 km [Bane and Brooks, 1979], and they propagate downstream at phase speeds of $30-40 \mathrm{~km} \mathrm{~d}^{-1}$ [Legeckis, 1979; Bane et al., 1981; Brooks and Bane, 1981]. Northeast of Cape Hatteras, the meanders develop with a broader band of periodicities, extending to longer periods. The amplitudes of the most energetic meanders (periods 4-100 days) grow rapidly within the first $200 \mathrm{~km}$ downstream of Cape Hatteras (Watts and Johns [1982] (hereinafter referred to as WJ82); Halliwell and Mooers [1983]). An observational dispersion curve constructed for the meanders in this region shows that phase speeds increase with increasing frequency (WJ82). For meanders with monthly periods, the phase speeds are $20 \mathrm{~km}$ $\mathrm{d}^{-1}$ and wavelengths are about $600 \mathrm{~km}$, whereas 4- to 5-day meanders have typical phase speeds and wavelengths of $40 \mathrm{~km}$ $\mathrm{d}^{-1}$ and $180 \mathrm{~km}$, respectively, similar to those south of Cape Hatteras. Farther downstream yet, east of $70^{\circ} \mathrm{W}$, largeamplitude meanders have been reported with wavelengths of $200-400 \mathrm{~km}$ and propagation speeds of 5-10 km d ${ }^{-1}$ [Hansen, 1970; Robinson et al., 1974; Halliwell and Mooers, 1983]. Thus, progressing downstream, the dominant meander periods lengthen and their phase speeds decrease. Moreover, as the meander amplitudes increase northeast of Cape Hatteras, the wavelengths apparently decrease [Halliwell and Mooers, 1983]. These regional charactẹristics of Gulf Stream meanders from the Straits of Florida to near $65^{\circ} \mathrm{W}$ are discussed further by Watts [1983].

The Gulf Stream path varies on seasonal to interannual

Copyright 1986 by the American Geophysical Union.

Paper number 6C0183.

$0148-0227 / 86 / 006 \mathrm{C}-0183 \$ 05.00$ time scales as well. Simple theoretical ideas [Veronis, 1981] have suggested that changes in current strength should be accompanied by lateral shifts in the position of the current, with the expectation that maximum transports would be accompanied by southerly shifts in the Gulf Stream position. Observations of seasonal variations in volume transports and path displacements tend to support this trend, although observations during the winter months have been sparse and the transports show considerable scatter [Iselin, 1940; Worthington, 1976].

In this paper we combine our measurements with those previously reported in WJ82 to obtain a relatively long-term set of in situ observations of Gulf Stream path fluctuations in the region just downstream of Cape Hatteras. Using an array of inverted echo sounders, measurements of the Gulf Stream's position were obtained continuously throughout several mooring periods from 1979 through 1982 . The more recent observations from November 1981 to July 1982 are documented here along with the spectral properties of the meanders observed during that time period. We present long-term statistics on the north wall location along four sections that span a downstream distance of $160 \mathrm{~km}$. Also, we examine the 36-month-long time series of the Gulf Stream displacements, obtained along one section $200 \mathrm{~km}$ northeast of Cape Hatteras, for evidence of a seasonal cycle. The combined data sets provide both longer measurement periods and greater spatial coverage, which allow us to refine the propagation and growth rate curves for meanders in the region just northeast of Cape Hatteras.

\section{Observational Setting and Methods}

The study area is located $140-375 \mathrm{~km}$ northeast of Cape Hatteras, where the Gulf Stream leaves the continental margin and flows into deeper water (Figure 1). The historical mean path of the north wall (center dashed line) is taken from Niiler and Robinson [1967]. The Gulf Stream north wall is within the region bounded by the upper and lower dashed lines approximately $90 \%$ of the time. The width of this " $90 \%$ envelope" more than doubles downstream through the area shown in Figure 1 (near Cape Hatteras, it is only $75 \mathrm{~km}$ wide, whereas at $71^{\circ} \mathrm{W}$ it exceeds $200 \mathrm{~km}$; that is, the Gulf Stream shifts laterally by more than its own width). 


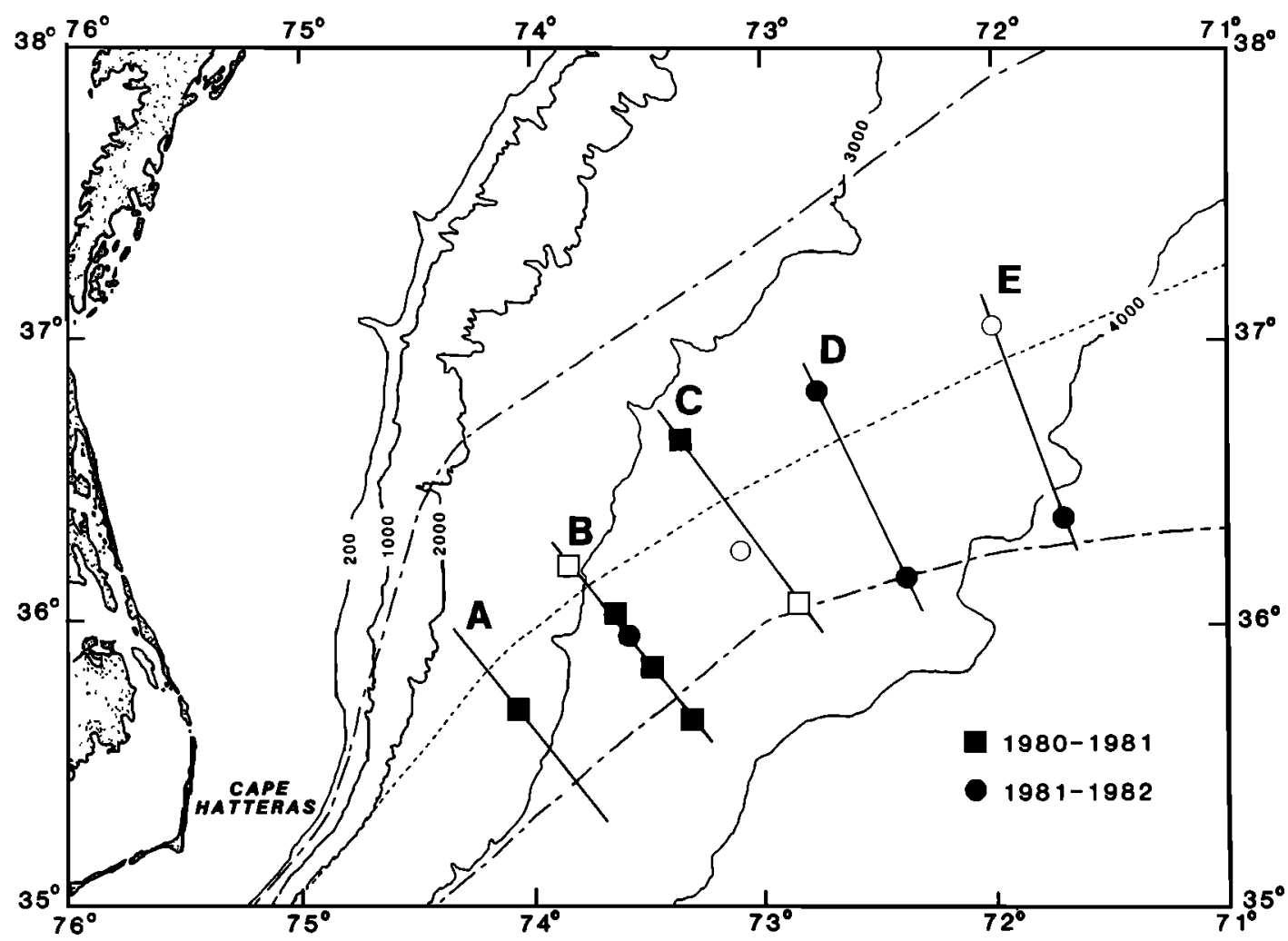

Fig. 1. Study area. IES sites are shown for the 1980-1981 (squares) and 1981-1982 (circles) deployment periods along lines A-E. Open symbols indicate sites where no data were collected due to data tape failures or instrument losses; solid symbols are sites with data. The historical mean location of the north wall is shown by the center dashed line, and the " $90 \%$ envelope" (see text) is delineated by the upper and lower long-short dashed lines.

At Cape Hatteras the coastal boundary consists of a rather narrow continental shelf and a steep continental slope. North of Cape Hatteras, the coastal boundary abruptly turns to the north. The slope region $(200-2000 \mathrm{~m})$ and the continental rise $(2000-4000 \mathrm{~m})$ broaden to the northeast.

Fluctuations of the Gulf Stream path were monitored by an array of inverted echo sounders (IESs). The development of the IES measurement technique and its application to this region are presented in the earlier investigations of Watts and Rossby [1977], Watts and Olson [1978], and WJ82. The IES is an instrument which is moored $1 \mathrm{~m}$ above the ocean floor and monitors the depth of the main thermocline acoustically. A sample burst of twenty $10-\mathrm{kHz}$ pings is transmitted every half hour, and the round trip travel times $(\tau)$ to the surface and back are recorded within the instrument. A detailed description of the instrument is given by Chaplin and Watts [1984].

Calibration expendable bathythermographs (XBTs) were taken at each IES site in order to convert the travel times into thermocline depths $(\xi)$ according to the relation: $\xi=M \tau+B$, where $M$ is $-19.5 \mathrm{~m} / \mathrm{ms}$ in this region (WJ82) and the intercept $B$ depends on the depth of the instrument. For practical purposes the main thermocline depth can be represented by the depth of an individual isotherm. For this study the depth of the $15^{\circ} \mathrm{C}$ isotherm $\left(Z_{15}\right)$ was chosen; it is the traditional indicator of the Gulf Stream since it is situated near the highest temperature gradient of the main thermocline. Simple application of this formula to our data would assume that all changes in $\tau$ result solely from changes in the depth of the permanent thermocline. However, $\tau$ also changes in response to seasonal warming and cooling of the surface layers $(<200$ $\mathrm{m})$. To minimize the errors in $Z_{15}$ that would result from these seasonal fluctuations, we remove the average seasonal variation of $\tau$ for the upper layers from our measurements prior to calculating $Z_{15}$ (see the appendix).

To study the meandering process, it is more meaningful to monitor changes in the Gull Stream's position than changes in $Z_{15}$. By assuming a mean cross-stream thermocline profile, the relative distance from each IES site to the north wall $\left(15^{\circ} \mathrm{C}\right.$ at $200 \mathrm{~m}$ ) can be determined by knowing the thermocline depth there. WJ82 gives a complete discussion of this technique, finding by comparisons with shipboard surveys that the position of the north wall determined by the ship and IES methods agreed within $5-8 \mathrm{~km}$ standard deviation. We made a slight improvement in their method of determining the north wall location by including a correction factor, which is used when there is an oblique crossing of the Gulf Stream (see the appendix).

Inverted echo sounders were deployed on various subsets of lines A-E during several deployments (summarized in Table 1) throughout a 3-year period from 1979 to 1982 . All the instruments were moored on the continental rise at water depths exceeding $2800 \mathrm{~m}$. Figure 1 indicates the IES sites for November 1980 to July 1981 and July 1981 to July 1982 . The instrument locations and the results from the first two deployment periods in 1979 and 1980 on lines A-C were reported in WJ82. In addition, instruments were maintained along line $B$ from July through November 1982 as part of an ongoing investigation of the meanders in this region.

During the 1980-1981 deployment period, lines A, B, and C were occupied. The downstream separation of $50 \mathrm{~km}$ was chosen because the displacement records reported in WJ82 were highly coherent at that spacing. At lines $B$ and $C$ the 
instruments were placed $80 \mathrm{~km}$ apart across the Gulf Stream to ensure that one IES was always under the steeply sloping thermocline. Two additional instruments were placed along line $\mathrm{B}$, reducing the spacing to $26 \mathrm{~km}$ in order to monitor changes in the slope and shape of the thermocline profile with the passage of meanders (but unfortunately the northernmost IES was lost). At line A, only one IES was needed to always remain under the strong baroclinic slope of the thermocline and monitor the Gulf Stream position, since the envelope of meandering is small in that region.

The array was extended to lines D and E during the 19811982 deployment period, and line A was not occupied. The downstream spacing was kept at $50 \mathrm{~km}$ except between $\mathrm{D}$ and $E$, where the spacing was increased to $73 \mathrm{~km}$. At lines D and E the cross-stream spacing of the IESs was $80 \mathrm{~km}$. Unfortunately, the instrument along line $\mathrm{C}$ was not recovered in July 1982 , and no data on the north wall position were obtained along that line for that period.

Altogether, line B was occupied during 36 months, line A during 21 months, and line $C$ during 18 months. Lines $D$ and $E$, occupied later, produced records of length 12 and 8 months, respectively.

\section{Displacement Time Series}

The time series of Gulf Stream north wall positions $[X(t)]$ are shown in Figure 2 for the 1980-1981 array on lines A-C and in Figure 3 for the 1981-1982 mooring period on lines B, $D$, and $E$. The 36-month-long time series obtained at line B from November 1979 to November 1982 is shown in Figure 4; it is the longest continuous record of the Gulf Stream's position in this region. These figures indicate the position where the north wall crosses each IES line as a function of time, measured from an origin defined as the historical mean north wall location at the cross-stream line. The line origins and orientations, measured from true north $\left({ }^{\circ} \mathrm{T}\right)$ at the origins, are given in Table 1. Negative values of $X$ indicate displacements onshore (northwest) of the origin; positive values are displacements which are offshore (southeast). The data have been lowpass filtered by convolution with a 24 -hour-half-width, Gaussian weighted window and subsampled at 12 -hour intervals.

The total range of the excursions of the north wall at line $A$, less than $60 \mathrm{~km}$, is the smallest of all the lines. Along line $B$, the range of the excursions increases to about $95 \mathrm{~km}$ for all mooring periods, with minimum northerly displacements of about $-35 \mathrm{~km}$ and maximum southerly displacements of about $60 \mathrm{~km}$. The range broadens downstream; by lines $D$ and $E$ the Gulf Stream can shift laterally about $150 \mathrm{~km}$, more than double the range at line $A$.

Meanders with periods of about 2-10 days are evident in all the time series, as are lateral shifts of the Gulf Stream with periodicities greater than 2-3 months. Typically, the north wall shifts laterally about $20 \mathrm{~km}$ with the passage of the 4- to 10-day meanders. These lateral translations of the Gulf Stream's axis have remarkably large velocities of $6-20 \mathrm{~km}$ $\mathrm{d}^{-1}$. Typically the rates decrease to less than $3 \mathrm{~km} \mathrm{~d}^{-1}$ for the longer-period ( $>30 \mathrm{~d}$ ) fluctuations, although lateral speeds as high as $15 \mathrm{~km} \mathrm{~d}^{-1}$ were observed during May-June 1981 (Figure 2).

The episodic nature of the north wall fluctuations is striking in Figure 4. Lateral shifts with periods greater than 10 days are evident during most of the deployments. Some of the more prominent events, such as those in November-December 1979 and May-June 1981, were caused by interactions with Gulf 

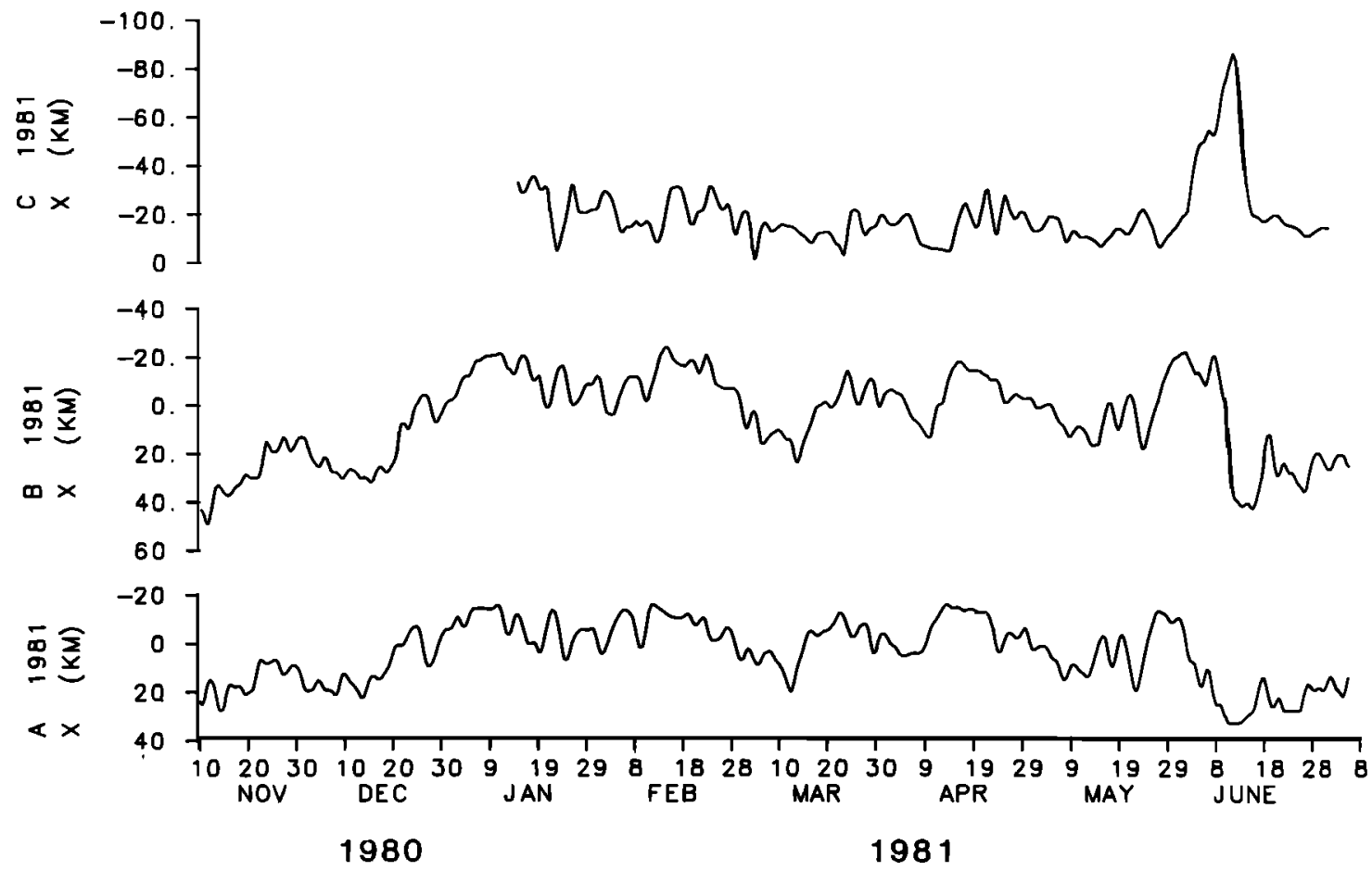

Fig. 2. Time series of lateral displacements $X$ of the Gulf Stream north wall for 1980-1981 along lines A, B, and C. Displacements are relative to the historical mean north wall location; positive (negative) values indicate displacements offshore (onshore) of the historical mean along the line. The data have been low-passed with a 24-hour filter.

Stream rings. There are relatively quiescent periods (e.g., April-May 1980 and July-August 1981), when the meander amplitudes are smaller $(<5 \mathrm{~km})$ and the shorter $(2-4$ days $)$ periodicities are dominant.

The displacements at lines A, B, and C (Figure 2) are visibly coherent for most periodicities, yet growth is apparent only between lines A and B. Based on the previous results of WJ82, growth probably occurred between lines $B$ and $C$ as well, but this was not accurately observed in the present measurements due to the failure of the southern IES on line C. High coherence can also be seen for the downstream records at lines D and $E$ (Figure 3) at most periodicities, yet line $B$ appears coherent with them only at the very long periods ( $>20$ days).

\section{Histograms of Gulf Stream Position}

Histograms of the north wall positions along the sections in our study area are shown in Figure 5, indicating the percentage of time that the Gulf Stream north wall is located within each $5-\mathrm{km}$ segment. These were constructed by combining all the observations we have collected at lines A-D. Only those sections with at least twelve months of observations are shown in Figure 5; thus line E, with only 8 months of data, has been omitted. The shapes of the histograms change dramatically with downstream distance. At lines A and B they are peaked with over half of the observations occurring within a narrow $(<20 \mathrm{~km})$ range. Farther downstream, however, at line $D$ the Gulf Stream can be found with about equal probability throughout the $145-\mathrm{km}$ excursion range. The mean and standard deviation of all the observations are shown by the large solid dot and heavy bar, respectively, at each section. These values are listed in Table 1 . Since these histograms are constructed as percent occurrence, care must be taken when comparing them because different numbers of observations as well as different observational periods were used.
During the 21-month measurement period at line A, over $50 \%$ of the observations of the north wall location were obtained within a $10-\mathrm{km}$ range centered about $8 \mathrm{~km}$ shoreward of the origin. The mean is $0.4 \mathrm{~km}$ offshore of the reference point and the standard deviation is $13.7 \mathrm{~km}$. The histogram is positively skewed with the mean about $5.5 \mathrm{~km}$ seaward of the most probable location. There appears to be a well-defined northern limit to the Gulf Stream's movements with the north wall very infrequently occurring more than $20 \mathrm{~km}$ shoreward of the origin. This corresponds closely with the location of the 1000 - to $2000-\mathrm{m}$ isobaths. It appears that the Gulf Stream movements may be restricted along this line due to the proximity of the continental slope. The southern limit is less distinct with the Gulf Stream occasionally shifting as far as $\mathbf{5 0}$ $\mathrm{km}$ offshore.

At line B, measurements of the north wall positions were made over a 36-month period, making our observations one of the most complete time series for this region. The mean location for the 3 years of data is $5.4 \mathrm{~km}$ offshore of the historical mean, and the standard deviation is $17.5 \mathrm{~km}$. This histogram is similar to that shown for line A; however, it is not as sharply peaked. About $50 \%$ of the time, the north wall can be found within $\pm 10 \mathrm{~km}$ (20 km range) of the line origin. The histogram is obviously skewed with the most probable position of the north wall about $10 \mathrm{~km}$ shoreward of the mean. The short onshore tail indicates that the Gulf Stream's movements along this line are apparently still restricted by the continental slope. The longer offshore tail implies that the southward shifting is not so constrained.

The mean of the 18 months of data obtained at line $\mathrm{C}$ is 8.8 $\mathrm{km}$ shoreward of the historical mean and the standard deviation is $20.3 \mathrm{~km}$. This histogram is more symmetric than that at line $\mathrm{B}$, with the mean about $5 \mathrm{~km}$ offshore of the most probable location of the north wall. About half of the time the 


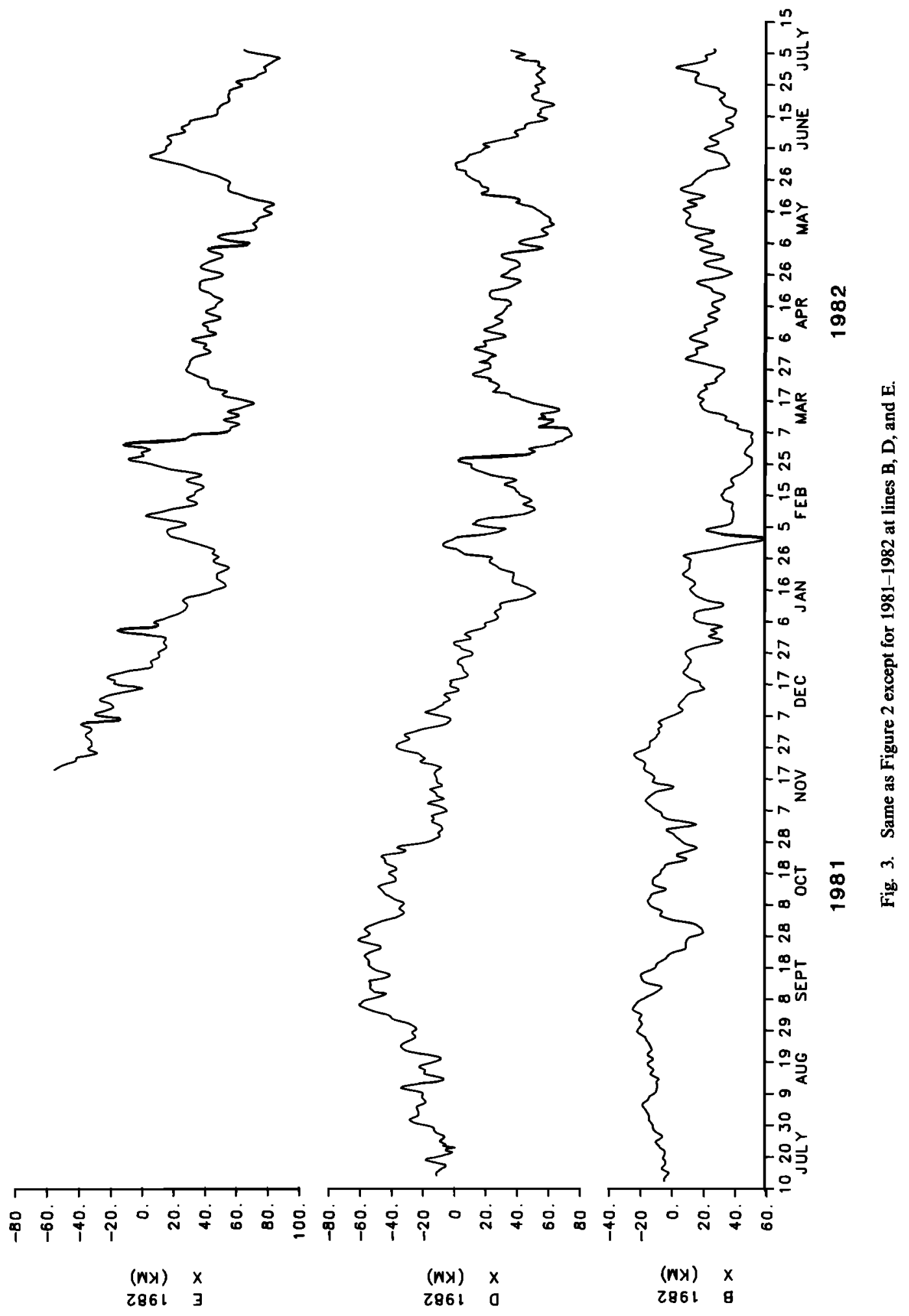



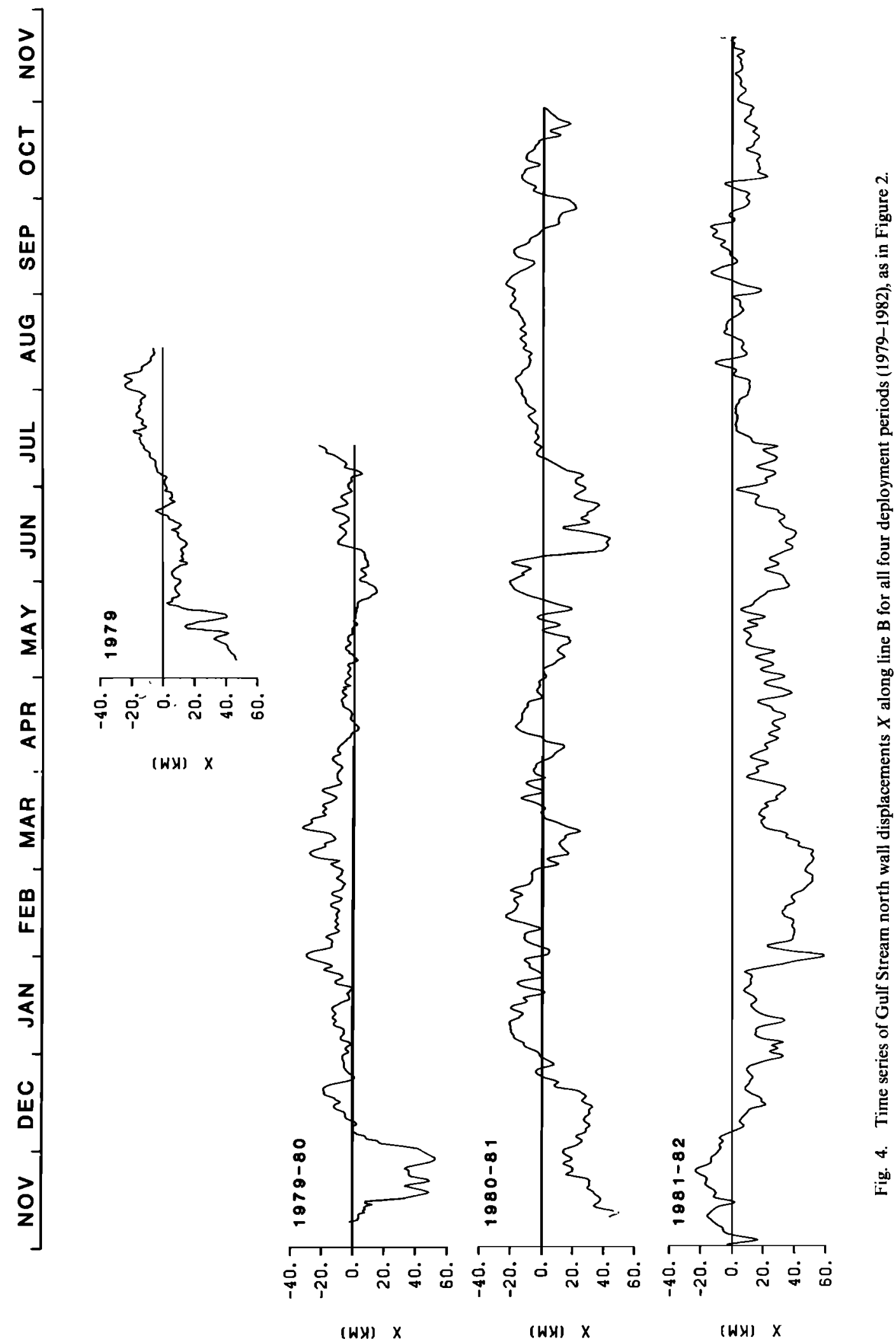


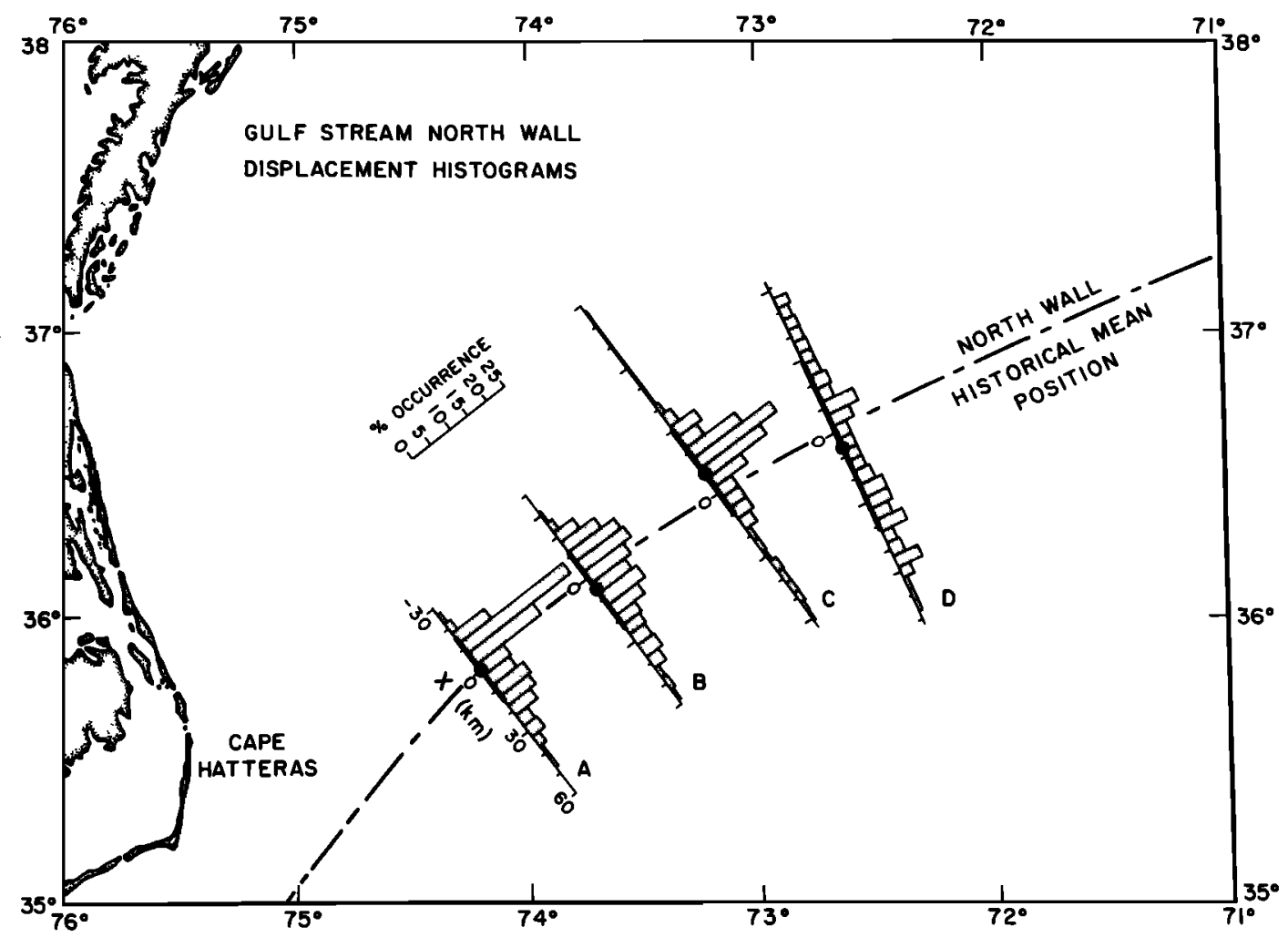

Fig. 5. Histograms of north wall position along lines A-D shown as percent occurrence. Means and standard deviations are shown by the large solid dots and heavy bars, respectively. The lateral scale on line A applies to all lines.

Gulf Stream is found within a $10-\mathrm{km}$ range centered $15 \mathrm{~km}$ shoreward of the reference point. Although the histogram appears more peaked than that at line $B$, this is due to differences in sample sizes. Line B has almost twice as many observations and covers twice the sampling period. When the histograms are compared for a common sampling period (not shown), the peak at line $C$ is less pronounced. The range at line $C$ is approximately $145 \mathrm{~km}$. The Gulf Stream could shift as far north as it did south; however, rarely did it shift more than $40 \mathrm{~km}$ shoreward. As on the other lines, it extended southward more frequently.

Farther downstream at line $\mathrm{D}$, the situation is strikingly different. The histogram is flat; the Gulf Stream north wall occurs with nearly equal probability throughout the $145-\mathrm{km}$ range and can shift equally north or south. The line $D$ mean is $7.5 \mathrm{~km}$ offshore of the historical mean, and the standard deviation of $34.7 \mathrm{~km}$ is almost triple that of upstream line $A$.

In summary, through the downstream course of our observational region, the Gulf Stream leaves the area where it sometimes directly brushes the continental margin to enter the area where it is a free jet. Correspondingly, the meander envelope width broadens and the position histograms become more symmetric, flatter, and wider.

\section{Seasonal Cycle}

We next examine the 3-year-long, continuous time series at line $B$ to test for a seasonal or annual cycle in the north wall fluctuations. Our measurements (Figure 4) show that there is considerable north/south variation in the Gulf Stream's position on time scales shorter than $\mathbf{3 0}$ days. Thus sampling biweekly or monthly, as previous investigations have done, may not be representative of the true monthly average. (For example, see the May-June 1981 feature, when the Gulf Stream position changes by about $60 \mathrm{~km}$ in 1 month.)
The displacements along line B were averaged by month for each calendar year. The monthly averages are shown in Figure 6 and are indicated by the lighter solid and dashed lines. The horizontal line indicates the mean of the total data set (5.4 $\mathrm{km})$. Additionally, monthly averages were calculated for the total data set and these are shown in Figure 6 by the bold line. On the average the Gulf Stream tends to be farthest north from July to September. Continuing through the fall and winter and into spring, it tends to shift farther offshore until May-June. There are secondary peaks in January (onshore) and in November-December (offshore). The peak-to-peak excursion of the 3-year mean curve at line $B$ is $20 \mathrm{~km}$.

Watts [1983] shows that the mean cross-stream profile of the thermocline changes seasonally. In the winter the thermocline slope is the steepest, and the offshore depth is the greatest; from spring through fall, the slope decreases slightly and the depth shoals by $\sim 70 \mathrm{~m}$. If a correction were applied to the IES records of Gulf Stream displacement to adjust for these small seasonal changes in the thermocline profile, the tendency would be to shift the winter/spring displacements about $5 \mathrm{~km}$ offshore relative to those for the summer/fall. Consequently, if we had included this effect, the peak-to-peak range of the mean curve in Figure 6 would have been slightly increased.

There is considerable variability in the annual mean location of the north wall. In 1981 the mean location of the north wall was $-1.0 \mathrm{~km}$, whereas in 1982 the mean was 17.8 $\mathrm{km}$, almost a $20-\mathrm{km}$ change from one year to the next. However, despite these yearly offsets, the seasonal trend within each year (Figure 6) is for more northerly positions to occur in the summer (July-September) and more southerly positions to be found in the spring (May-June).

Our mean seasonal cycle of Gulf Stream positions is compared in Figure 7 with historical reports of seasonal variations in position as well as in measures of current strength. Hachey 


\section{GULF STREAM DISPLACEMENT}

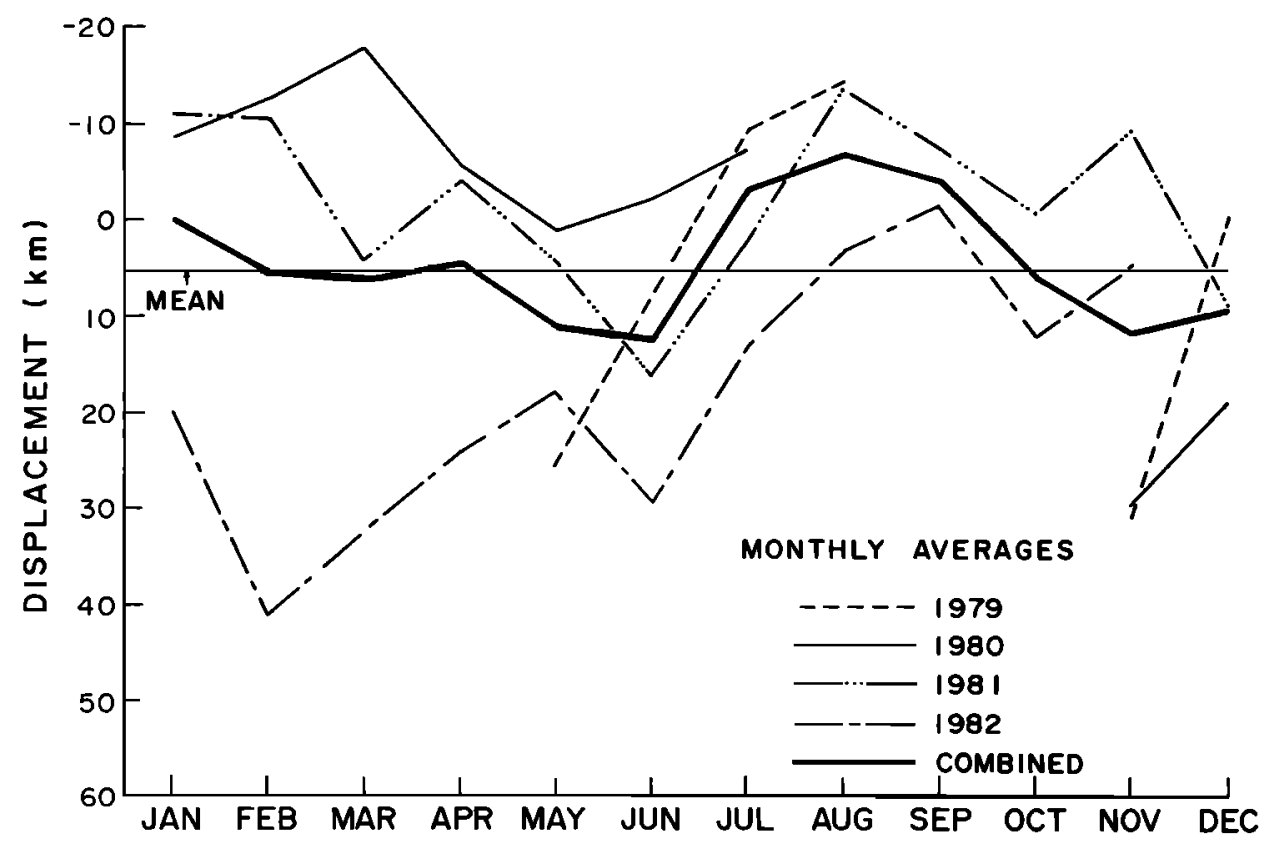

Fig. 6. Monthly average north wall displacements for 1979-1982 at line $B$. The heavy line indicates the overall average for each month. The mean location for the total data set $(5.4 \mathrm{~km})$ is indicated by the horizontal line.

[1939] reported on surface thermograph measurements of the Gulf Stream position near $65^{\circ} \mathrm{W}$, taken approximately twice a month during a 7-year period on 161 transects from Boston to Bermuda. His monthly average curve, plotted in Figure $7 b$, shows that in general the Gulf Stream was located to the south in the spring (April-May) and in the fall (OctoberNovember) and northerly positions occurred in the summer (August-September) and in January. Fuglister [1972] reported a somewhat different seasonal cycle with offshore movements occurring in the early spring and shoreward movements in October-November (Figure 7c). Not only is his cycle shifted slightly in time from these other two, but there are single rather than double onshore and offshore extrema. His results are based on position data from only one 12-month period (but averaged along the path from $75^{\circ}$ to $50^{\circ} \mathrm{W}$ ) and therefore may not be representative of the average cycle over many years.

Direct measurements of transport are difficult to obtain; thus indirect methods have been used to infer changes in its magnitude. Montgomery [1938] suggested that changes in sea level across a current, which are geostrophically associated with changes in surface velocities, might in turn be indicative of the total transport changes. More recently, Blaha [1984] used tide gauges only along the western edge of the Gulf Stream as indicators of the current strength. Results from both sea level methods (Figures $7 d$ and $7 e$ ) are quite similar. They suggest a seasonal cycle with maximum (surface) transports occurring in the winter and summer and with minima occurring in the spring and fall.

A comparison of our seasonal cycle of north wall position with that of surface transport inferred from sea level shows that the surface transport peaks lag peaks in position by about 2 months. The secondary, late-winter peak is more prominent in the transport cycle than in the position cycle. Since the sea level measurements pertain primarily to the region upstream of Cape Hatteras, this shift may reflect regional differences in the timing of the annual cycle.

Regional variations in the timing of the annual cycle have been previously noted. Using surface current speeds measured by ship drift, Fuglister [1951] found that minimum speeds occurred throughout the Gulf Stream system in the fall, whereas maximum current speeds occurred at different times of the year depending on the region. Higher velocities were found in the southern Gulf Stream sections during the summer, whereas northeast of Cape Hatteras they occurred in the spring, and east of the Grand Banks they occurred in the late winter. Fuglister's [1951] current speed estimates for the region northeast of Cape Hatteras are shown in Figure $7 f$. At first sight, the cycle appears to differ from the seasonal pattern mentioned above, but in fact it has two minima, and the period of highest speeds corresponds to our period of most southerly position.

Recently, Halkin and Rossby [1985] calculated transports in the upper $2000 \mathrm{~m}$ from 14 sections made at 2-month intervals for $2 \frac{1}{2}$ years across the Gulf Stream very near line B using an absolute velocity profiler. There was considerable scatter in the transport measurements and in their monthly averages; however, the median total transport of $96.9 \mathrm{~Sv}$ for the 6month period from February to July was significantly different at the $90 \%$ level from the median total transport of $78.0 \mathrm{~Sv}$ for the other half of the year. They reported a small but statistically significant correlation $\left(r^{2} \approx 0.37\right)$ between the baroclinic component of transport and the Gulf Stream position, which corroborates the qualitative similarity of seasonal trends shown in Figure 7.

While additional measurements will be required to clearly establish the relationships and seasonal cycles of position and various measures of current strength, a clear pattern can be seen in the measurements (summarized above) from many different years: The Gulf Stream tends to flow along more northerly paths in the summer/fall when the current is the weakest, and along more southerly paths in the winter/spring when the current is the strongest.

\section{SPectra ANd Cross SPeCtra}

The 36-month-long time series at line $B$ enabled us to obtain spectral estimates for long-period motions and to look for seasonal differences in the spectra. The continuous 2-year 

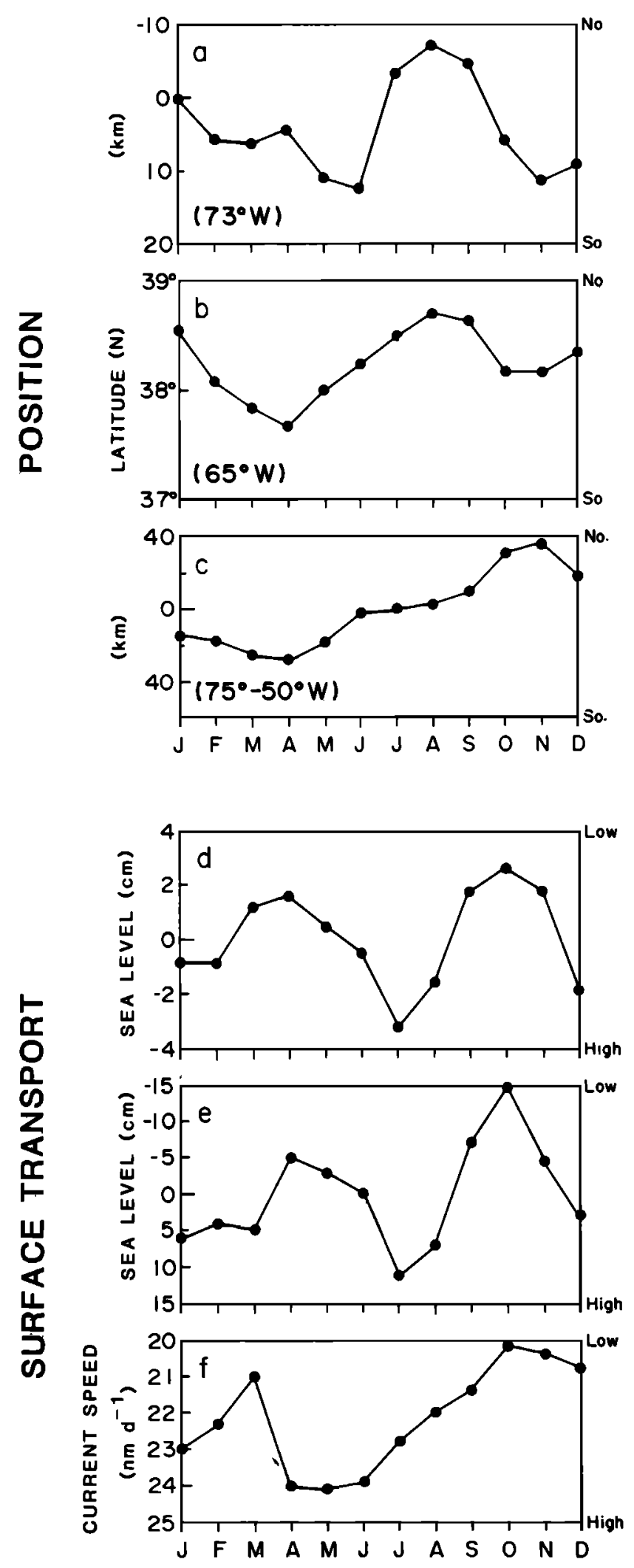

Fig. 7. Seasonal cycles of position (Figures $7 a-7 c$ ) and transport (Figures $7 d-7 f$ ) from several investigations plotted versus month. (a) Three-year averages of north wall position at $73^{\circ} \mathrm{W}$ repeated from Figure 6. (b) Seven-year averages of positions at $65^{\circ} \mathrm{W}$ from Hqchey [1939]. (c) Along-stream averages of position between $50^{\circ}$ and $75^{\circ} \mathrm{W}$ from one year from Fuglister [1972]. (d) Average sea level residuals at Norfolk for 1955-1975 from Blaha [1984]. (e) Sea level difference between Bermuda and Charleston averaged over 47 months from Montgomery [1938]. ( $f$ ) Multiyear averages of surface current speeds for the region northeast of Cape Hatteras from Fuglister [1951].

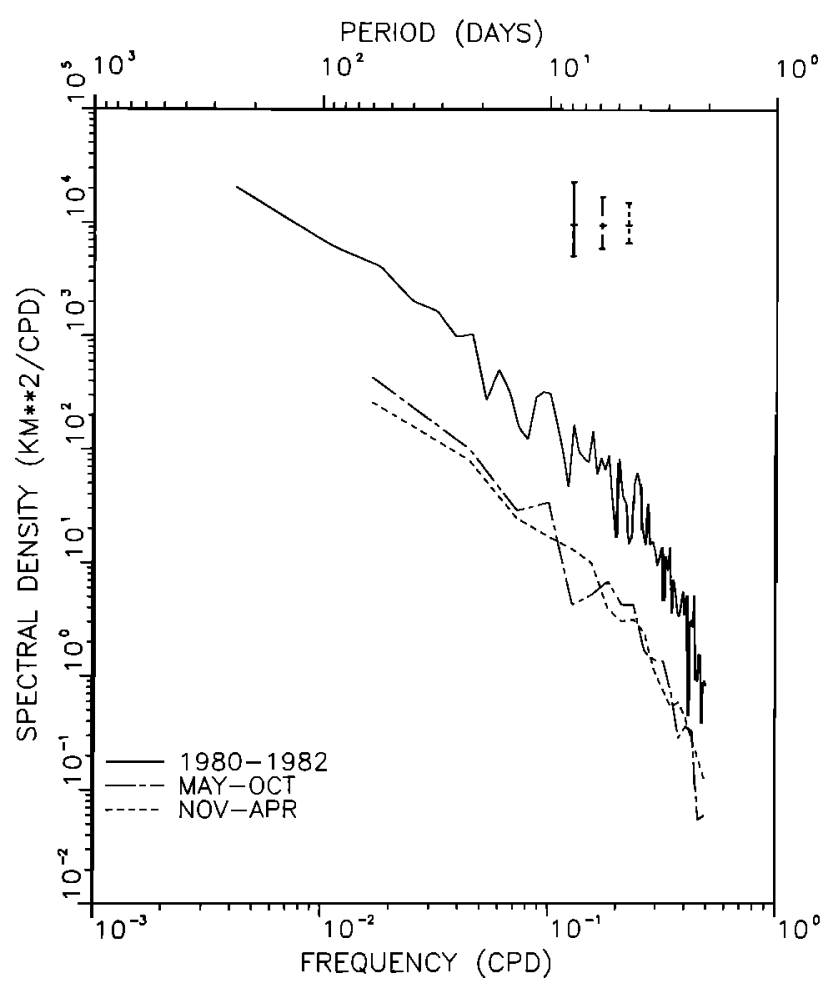

Fig. 8. Power spectra of path displacements at line $B$ for the continuous 2-year mooring period (solid) and, separately averaged, for the fall/winter (dashed) and spring/summer (long-short dashed) seasons. The seasonal spectra have been offset downward by a factor of 10 for clarity. The error bars, drawn with the corresponding line symbols, indicate the $90 \%$ confidence intervals.

mooring period from November 1980 to November 1982 was used to obtain band-averaged spectral estimates for periods as long as 8 months. These are shown in Figure 8 . The data were detrended and windowed with a cosine taper function on the first and last $10 \%$ of the record. Five adjacent bands were averaged giving 10 degrees of freedom for each estimate (Table 2). The spectrum is red even at the long periods, with a slope of -1 to -2 . For periods less than 4 days it falls very rapidly with a slope of -5 to -6 . There are no significant peaks in the spectrum, since the $90 \%$ confidence limit error bars exceed the small amount of structure present in the spectra.

To check for seasonal changes in the character of the meanders, the full 3 years of data from line B were divided into five 6-month records. These were separated into fall/winter (November-April) and spring/summer (May-October) seasons, and the spectra are ensemble averages of two or three of these members. Table 2 summarizes the spectral bandwidths and degrees of freedom for the two spectra, and the spectra are shown in Figure 8, offset downward by one decade from the full time series spectrum at line B. The spectra for both seasons are red, featureless, and indistinguishable in structure. Over $98 \%$ of the variance is associated with periods longer than 4 days for both seasons. The total variance for the November-April period is only two thirds that of the MayOctober period; however, the range of the total variance from year to year for either given season was greater than the difference between the seasons. Thus it appears that unlike the region upstream of Cape Hatteras where Brooks and Bane [1983] found seasonal differences in the spectral properties of velocity component fluctuations related to meandering, there are no significant differences in the meander properties in this region.

The spectra for path displacements on lines A-C in 1980- 
TABLE 2. Characteristics of the Power Spectra Shown in Figures 8, 9, and 10

\begin{tabular}{cccccc}
\hline $\begin{array}{c}\text { Time } \\
\text { Series }\end{array}$ & $\begin{array}{c}\text { Number of } \\
\text { Members }\end{array}$ & $\begin{array}{c}\text { Number of } \\
\text { Samples/ } \\
\text { Member }\end{array}$ & $\begin{array}{c}\text { Number of } \\
\text { Bands } \\
\text { Averaged }\end{array}$ & $\begin{array}{c}\text { Degrees of } \\
\text { Freedom }\end{array}$ & $\begin{array}{c}\text { Band } \\
\text { Width, } \\
\text { cpd }\end{array}$ \\
\hline Line B & & & & & \\
2 Year & 1 & 1440 & 5 & 10 & $6.9444 \mathrm{E}-03$ \\
May-Oct. & 2 & 360 & 5 & 20 & $2.7780 \mathrm{E}-02$ \\
Nov-April & 3 & 360 & 5 & 30 & $2.7780 \mathrm{E}-02$ \\
1980-1981 & 3 & 200 & 4 & 24 & $4.0000 \mathrm{E}-02$ \\
Line A & 3 & 200 & 4 & 24 & $4.0000 \mathrm{E}-02$ \\
Line B & 2 & 200 & 4 & 16 & $4.0000 \mathrm{E}-02$ \\
Line C & 2 & 400 & 4 & 16 & $2.0004 \mathrm{E}-02$ \\
1981-1982 & 2 & 400 & 4 & 16 & $2.0004 \mathrm{E}-02$ \\
Line B & 2 & 200 & 4 & 16 & $4.0000 \mathrm{E}-02$ \\
Line D & 2 & & & & \\
Line E & 2 & & & & \\
\hline
\end{tabular}

All the spectra are ensemble averages of two or three members, except for the line B spectrum, which is determined from the full record. The length of each member is given as the number of samples, where the sampling interval is 12 hours. Read 6.9444E -03 as $6.9444 \times 10^{-3}$.

1981 are shown in Figure 9. Spectral bandwidths and degrees of freedom are listed in Table 2 . The spectra all fall off rapidly (slopes about -6 ) for all periods shorter than 4 days. For the periods longer than 4 days, the slopes vary from about -1.5 to -2 , which are similar to those reported in WJ82. For the 1980-1981 deployment period, however, the total variance is greater than that reported in WJ82 by almost a factor of 2 . Between lines A and B, the variance doubles in the $50-\mathrm{km}$ downstream distance. No comparable further increase was seen at line $C$, but this may be due, in part, to inadequate tracking of the north wall along this line because of an instrument failure.

The corresponding power spectra for the 1981-1982 period on lines B, D, and $\mathrm{E}$ are shown in Figure 10. Table 2 also lists bandwidths and degrees of freedom for these lines. (Note that line $\mathrm{E}$ has half the resolution because the good record was only half as long.) The shapes of the three spectra are quite similar, showing no significant spectral peaks. The variance doubles in the $111-\mathrm{km}$ separation between lines $B$ and $D$, but

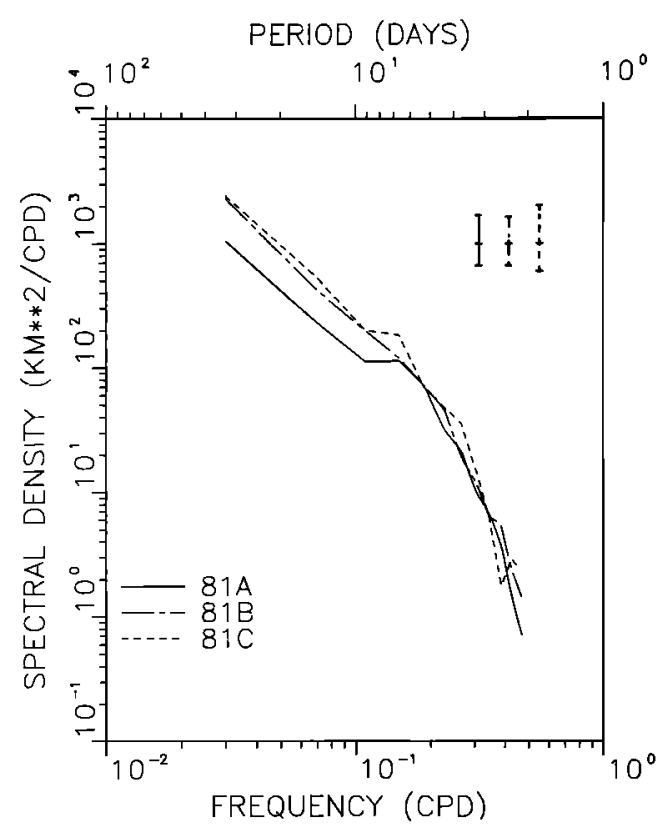

Fig. 9. Power spectra of path displacements at sections A, B, and $C$ for $1980-1981$. Error bars indicate the $90 \%$ confidence intervals, drawn with the corresponding line symbols. the total variance remains nearly constant between lines D and $E$, separated by $73 \mathrm{~km}$.

The spectra at line B for the 1980-1981 and the 1981-1982 mooring periods are essentially the same. This indicates that even though in 1982 the Gulf Stream was offset about one standard deviation $(20 \mathrm{~km})$ to the south from its 1981 average position, the energy released to the meandering process is the same.

Figures 11 and 12 show the coherence and phase delays between pairs of lines for the 1980-1981 and 1981-1982 mooring periods, respectively. The $81 \mathrm{AB}$ pair is highly coherent for all periods greater than 2 days and the $81 \mathrm{BC}$ and $81 \mathrm{AC}$ pairs are coherent for almost all periods longer than 4 days (Figure 11). The lower coherence between the $81 \mathrm{AC}$ and $81 \mathrm{BC}$ pairs can be attributed to the poor measurements at line $\mathrm{C}$. By comparison, in the earlier (1979-1980) deployment results (WJ82), the BC pair had higher coherence than $A B$, when the tracking accuracy (noise) along all three lines was the same and the variance (signal) doubled from $A$ to $B$ and again from $B$ to $C$. Further comparison of these results with those in WJ82 shows that the coherence between the AB pair is substantially greater during $1980-1981$ than $1979-1980$. We at-

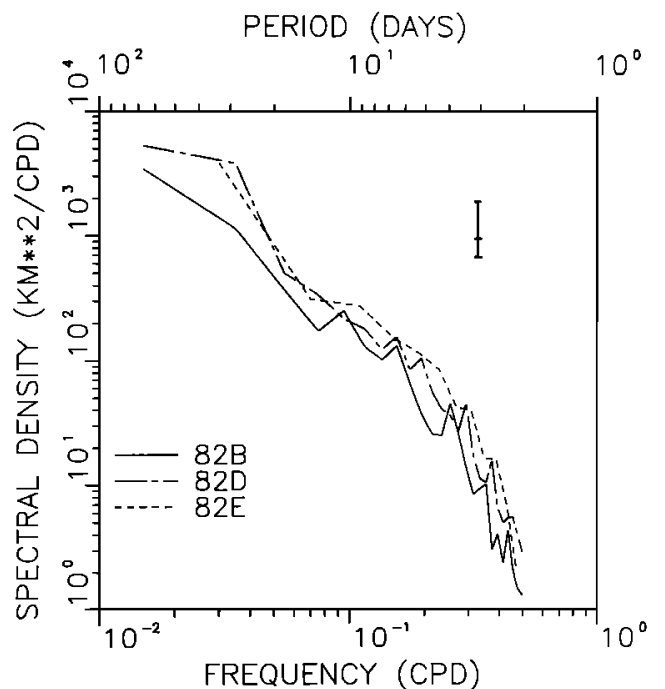

Fig. 10. Power spectra of path displacements at sections B, D, and $E$ for 1981-1982. Error bar indicates the $90 \%$ confidence interval for all three spectra. 

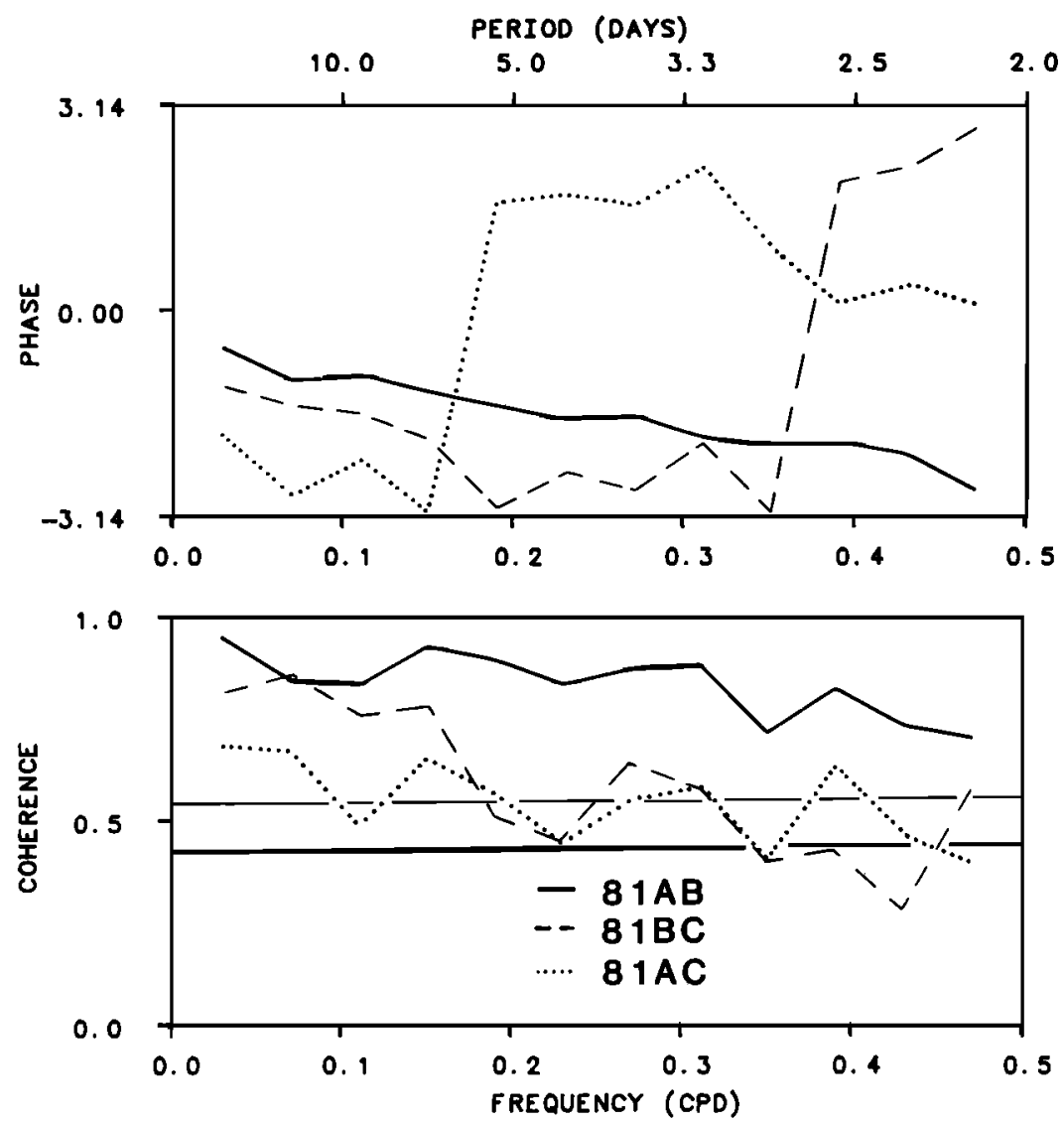

Fig. 11. Ensemble-averaged coherence and phase between line pairs AB, BC, and AC for 1980-1981. In the coherence plot the $90 \%$ significance level is indicated by the bold horizontal line $(0.435)$ for the AB pair and by the light horizontal line (0.529) for the $\mathrm{BC}$ and $\mathrm{AC}$ pairs.

tribute the higher coherence to the larger signal-to-noise ratio which was observed during $1980-1981$; that is, the total variance increased twofold between deployment periods, while the tracking accuracy remained constant.

The coherences for the 1981-1982 period, shown in Figure 12, are somewhat lower than those for 1980-1981 for two reasons: (1) The tracking record at line $E$ was from a single instrument and consequently of lower quality. Since the width of the meandering envelope is large in this region, at least two IESs are required along a section to ensure that one of them is under the steep thermocline slope at all times. (2) The downstream separations between line pairs were larger than in the earlier deployment period (e.g., $111 \mathrm{~km}$ for $82 \mathrm{BD}$ but $50 \mathrm{~km}$ for $81 \mathrm{AB}$ ). Nevertheless, the $82 \mathrm{DE}$ pair is coherent for all periods longer than 4 days, but the 82BD and 82BE pairs are coherent only at long periods ( $>20$ days) and for periods of about 7-8 days.

Altogether, we find that all meander periodicities from 4 to 100 days are coherent at downstream separations of 50-70 $\mathrm{km}$, but only a band near 7-8 days and periodicities longer than 20 days are coherent at 111 and $184 \mathrm{~km}$ distances. Visual inspection of the time series plots in Figures 2 and 3 tends to confirm these observations.

\section{Meander Dispersion and Growth}

The sense of the phase lag $\phi$ indicates that the meanders are propagating downstream (Figures 11 and 12). The phase speed $c_{r}$ may be determined as $c_{r}=\delta s(2 \pi f / \phi)$, where $\delta s$ is the downstream spacing between the two sections and $f$ is frequency. Note that $\phi / f$ is the slope of a line from the origin to the plotted phase curves, which decreases considerably (as $c_{r}$ increases) with increasing frequency.

WJ82 represented the path variability as downstreampropagating waves in the form exp $(i(k s-\omega t))$. Downstream spatial growth $\kappa$ can be represented by a complex wave number $k=k_{r}-i \kappa(\kappa>0)$. When viewed in a coordinate system that is moving downstream with the meanders, temporal growth $\sigma$ can be represented by complex frequency $\omega=\omega_{\text {r }}$ $+i \sigma$. The growth rates may be estimated from the spectral ratios $\left(G_{2} / G_{1}\right)$ at the various lines, where $\kappa=\ln \left(G_{2} / G_{1}\right) / 2 \delta s$ and $\sigma=\kappa c_{r}$ (see WJ82).

Phase speeds are calculated and listed in Table 3 for the three most coherent section pairs of the two deployment periods. To obtain a uniform set of output frequencies for the three line pairs, the displacement time series for each crossstream section were subdivided into several shorter segments, "members," with a common length of 100 days. The spectra were determined by ensemble averaging two or more of these members, and the cross spectra and phase delays between the line pairs were subsequently calculated. Summarized in Table 3 are the ensemble-averaged dispersion relationships (complex) and error estimates, using all data since 1979 , for meanders propagating between lines $A B, B D$, and DE (listed in order of increasing downstream position). Figure 13 shows the phase speed $c_{r}$ as a function of downstream wave number $k_{r}$ for the two longest and most coherent section pairs, 79-81AB and $82 \mathrm{BD}$. Only values whose coherence exceeded the $90 \%$ significance level are plotted. The uncertainty level in $c_{r}$ (at $90 \%$ confidence) is about $\pm 17 \%$ and $\pm 20 \%$, respectively, for the 79-81AB and 82BD pairs. (The group speed, $c_{g}=c_{r}+k \delta c_{r} /$ 

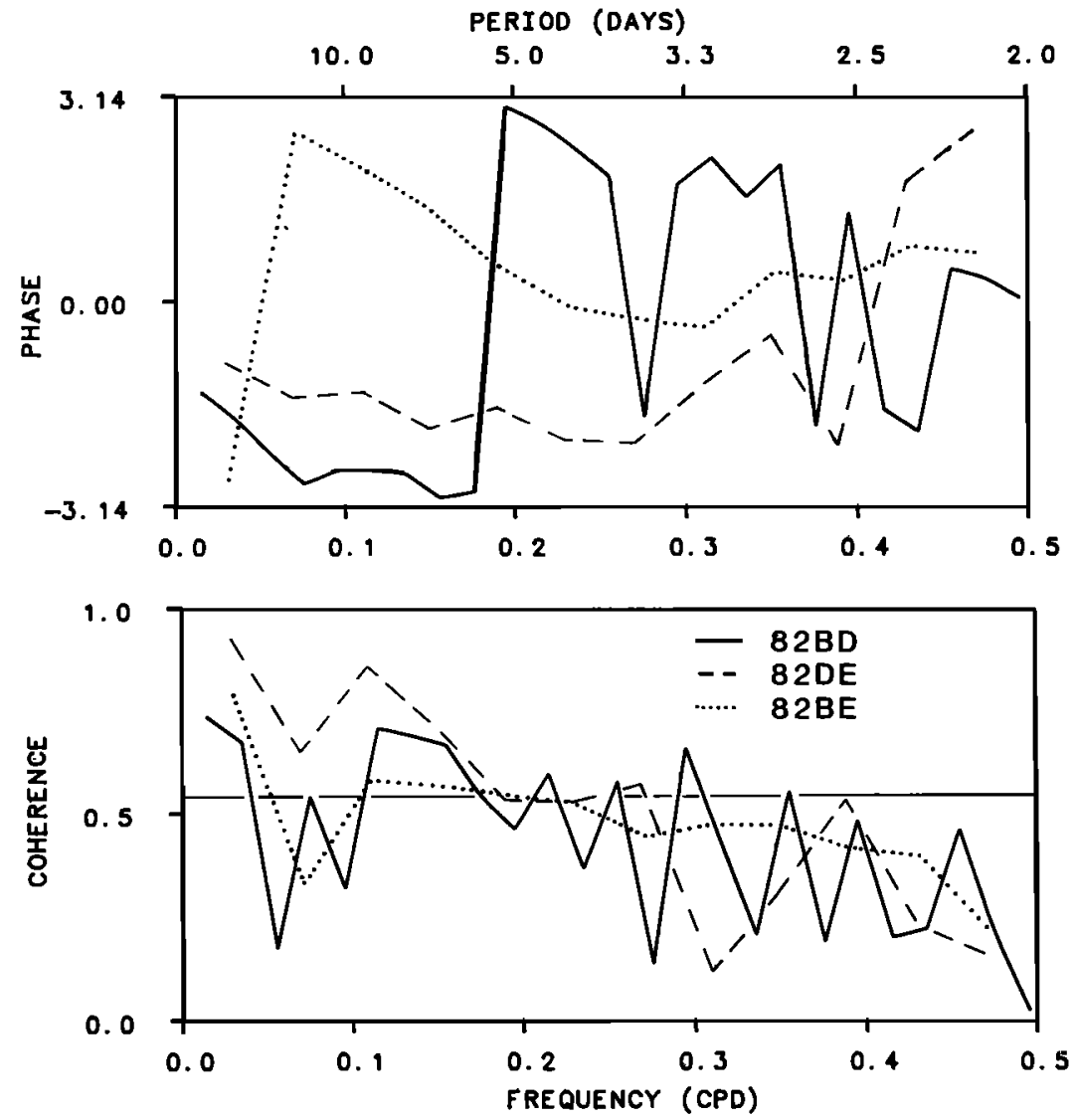

Fig. 12. Ensemble-averaged coherence and phase between pairs BD, DE, and BE for 1981-1982. In the coherence plot the horizontal line (0.529) indicates the $90 \%$ significance level.

$\delta k$, is approximately twice the values of $c_{r}$ shown in Figure 13, ranging from about $25 \mathrm{~km} \mathrm{~d}-1$ for $k=1.3 \times 10^{-2} \mathrm{~km}^{-1}$ to a peak of about $75 \mathrm{~km} \mathrm{~d}^{-1}$ near $k=2.3 \times 10^{-2} \mathrm{~km}^{-1}$.)

The dispersion relationships obtained for the two line pairs and for different time periods are essentially indistinguishable. The phase speeds decrease smoothly, from over $45 \mathrm{~km} \mathrm{~d}^{-1}$ for meanders with periods and wavelengths (4 days, $180 \mathrm{~km})$ to about $14 \mathrm{~km} \mathrm{~d}^{-1}$ for the ( 33 days, $460 \mathrm{~km}$ ) meanders. Interestingly, near wave numbers of $1.5-2.0 \times 10^{-2} \mathrm{~km}^{-1}$, the dispersion curve shows an inflection point of slightly lower speeds, which appears to be present consistently with the different data sets and line pairs.

We consider this dispersion relation to be an improvement over that determined in WJ82 because it is based on consider- ably more data and incorporates the earlier results into the ensemble averages. The observations extend to lower frequencies than were possible earlier. Values for $c_{r}$ are about $30 \%$ lower than those reported in WJ82 for meanders with periods and wavelengths ( $>10$ days, $>300 \mathrm{~km}$ ) but are essentially the same for the shorter-period, shorter-wavelength meanders.

Our study area is located in the region where Halliwell and Mooers [1983] reported frequent capture of warm-core rings by the Gulf Stream. Perturbations of the Gulf Stream path can be caused by these ring-stream interactions in addition to the freely propagating meanders. Two of these events were observed along lines A, B, and C during the fall of 1979 and the spring of 1981 . In both cases the perturbations caused by

TABLE 3. Propagation Speeds and Growth Rates for the 79-81AB, 82BD, and 82DE Line Pairs

\begin{tabular}{|c|c|c|c|c|c|c|c|c|c|c|c|c|c|c|c|c|}
\hline \multirow[b]{2}{*}{$\begin{array}{c}T, \\
\text { days }\end{array}$} & \multirow[b]{2}{*}{$\begin{array}{c}f, \\
\operatorname{cpd}^{*}\end{array}$} & \multicolumn{3}{|c|}{$c_{r}, \mathrm{~km} \mathrm{~d}^{-1}$} & \multicolumn{3}{|c|}{$k_{r}, 10^{-2} \mathrm{~km}^{-1}$} & \multicolumn{3}{|c|}{$\lambda, \mathbf{k m}$} & \multicolumn{3}{|c|}{$\kappa, 10^{-2} \mathrm{~km}^{-1}$} & \multicolumn{3}{|c|}{$\sigma, \mathrm{d}^{-1}$} \\
\hline & & $\begin{array}{c}79- \\
81 \mathrm{AB}\end{array}$ & $82 \mathrm{BD}$ & $82 \mathrm{DE}$ & $\begin{array}{c}79- \\
81 \mathrm{AB}\end{array}$ & $82 \mathrm{BD}$ & 82DE & $\begin{array}{c}79- \\
81 \mathrm{AB}\end{array}$ & 82BD & 82DE & $\begin{array}{c}79- \\
81 \mathrm{AB}\end{array}$ & 82BD & 82DE & $\begin{array}{c}79- \\
81 \mathrm{AB}\end{array}$ & 82BD & 82DE \\
\hline 33.3 & 0.03 & 14 & 13.9 & 14.8 & 1.31 & 1. & 1.28 & 479 & 463 & 49 & 0.84 & 0.31 & -0.24 & 0.120 & 0.043 & -0.035 \\
\hline 14.3 & 0.07 & 20.7 & 18.6 & 21.7 & 2.13 & 2.36 & 2.03 & 30 & 26 & 310 & 0.63 & 0.20 & 0.20 & 0.130 & 0.037 & 0.044 \\
\hline 9.1 & 0.11 & 31.6 & 29.9 & 36.3 & 2.19 & 2.31 & 1.90 & 28 & 272 & 330 & 0.58 & 0.02 & 0.00 & 0.184 & 0.006 & 0.001 \\
\hline 6.7 & 0.15 & 36.8 & 36.8 & 35.3 & 2.55 & 2.56 & 2.6 & 24 & 246 & 23 & 0.10 & 0.08 & 0.03 & 0.037 & 0.029 & 0.012 \\
\hline 5.3 & 0.19 & 41.7 & 43.2 & 53.5 & 2.86 & 2.76 & 2.23 & 220 & 227 & 281 & 0.16 & 0.28 & -0.03 & 0.067 & 0.120 & -0.017 \\
\hline 4.3 & 0.23 & 38.9 & 43.7 & 49.2 & 3.71 & 3.30 & 2.94 & 169 & 190 & 214 & 0.31 & 0.29 & 0.50 & 0.121 & 0.129 & 0.245 \\
\hline \multicolumn{17}{|c|}{$90 \%$ Confidence Interval } \\
\hline & & $\pm 17 \%$ & $\pm 20 \%$ & $\pm 25 \%$ & $\pm 17 \%$ & $\pm 20 \%$ & $\pm 25 \%$ & $\pm 17 \%$ & $\pm 20 \%$ & $\pm 25 \%$ & \pm 0.47 & \pm 0.27 & \pm 0.57 & $\pm 70 \%$ & $\pm 100 \%$ & \\
\hline
\end{tabular}

*A common measurement period length (100 days) for each ensemble member was chosen to give a uniform set of output frequencies for this comparison of three line pairs. 


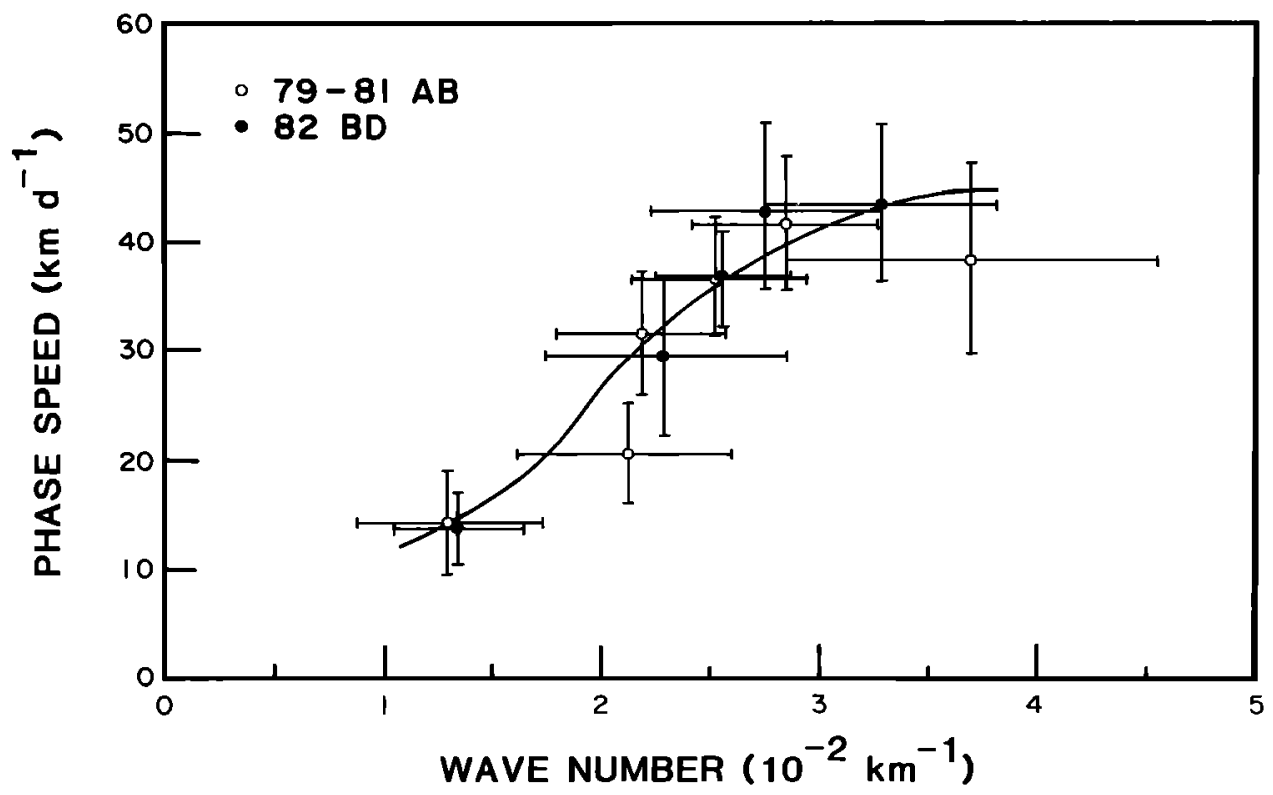

Fig. 13. Phase speed $c_{r}$ plotted versus wave number $k_{r}$. Open circles represent phase speeds calculated at 50-km separation between lines A and B for 1979-1981 (79-81AB). Solid circles represent phase speeds calculated at 111-km spacing between lines B and D for 1981-1982 (82BD). The error bars indicate the $90 \%$ confidence limits. The curve is merely a guide to the eye.

ring coalescence were observed to intensify and propagate downstream. The November-December 1979 and the MayJune 1981 events have periods of about 50 and 30 days, respectively, and delay times corresponding to phase speeds of 6.5 and $10.5 \pm 2 \mathrm{~km} \mathrm{~d}^{-1}$. These characteristics resemble those for freely propagating meanders, shown in Figure 13.

The spatial and temporal growth rates $(\kappa$ and $\sigma$ ) for meanders in this region, as determined by the full data sets on line pairs $A B$ and BD, are plotted versus wave number in Figure
14. Only values whose coherence exceeds the $90 \%$ significance level are shown. The $\kappa$ and $\sigma$ estimates for 79-81AB are very similar to those reported in WJ82, and the 79-81AB and 82BD estimates show the same features: both have bands of rapid growth at long (10-33 days) and short (4-5 days) periods, separated by a band of minimal growth near 6-8 days. Wavelengths in the growth band at long periods are typically 300 $500 \mathrm{~km}$ and about $200 \mathrm{~km}$ in the growth band at short periods. In both growth regimes, meander amplitudes show
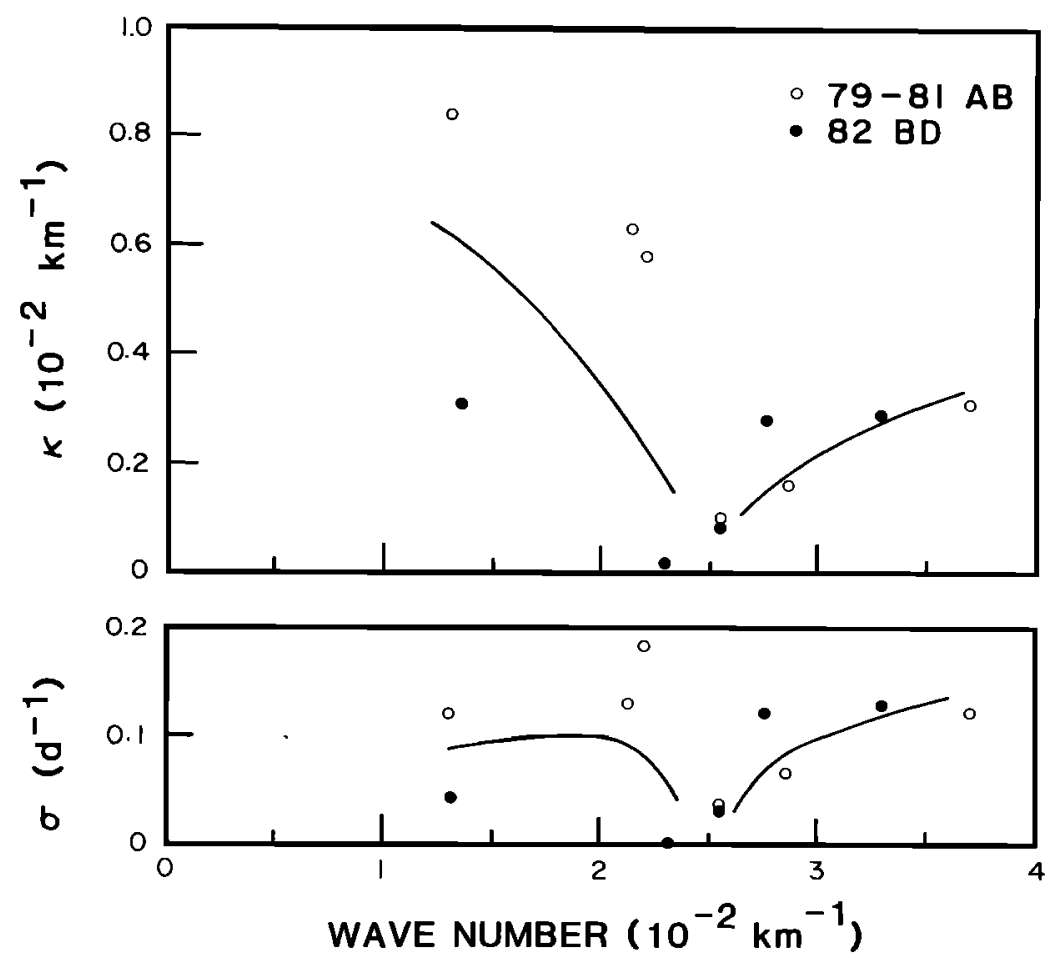

Fig. 14. Spatial growth rate $\kappa$ and temporal growth rate $\sigma$ plotted for all coherent points versus wave number $k_{r}$. Open and solid circles are for sections $\mathrm{AB}$ and $\mathrm{BD}$, respectively, as in Figure 13. The curves are merely guides to the eye. 
remarkably rapid $e$-fold growth in distances $\left(\kappa^{-1}\right)$ and times $\left(\sigma^{-1}\right)$ comparable to the wavelengths and periods, respectively. The uncertainty intervals for $\kappa$ and $\sigma$ are about $70 \%$ or more, as listed in Table 3. The growth rates for long-period $(>10$ days), long-wavelength $(>300 \mathrm{~km})$ meanders are somewhat higher at the upstream pair 79-81AB than the downstream pair $82 \mathrm{BD}$ (as well as $82 \mathrm{DE}$, which is noisier and not plotted). By contrast, in the shorter-period, shorter-wavelength band the growth rates are nearly the same downstream as they are nearer Cape Hatteras.

\section{Summary and Conclusions}

From 1981 to 1982 we maintained IESs along subsets of five cross-stream lines within a downstream distance of 375 $\mathrm{km}$ of Cape Hatteras. Combining our measurements of the Gulf Stream displacements with those reported in WJ82 for the 1979-1980 period, we have been able to obtain long-term statistics on the north wall location and on the propagation and growth characteristics of the meanders in this region.

The distribution of the path displacements are compared along four cross-stream sections, spanning a total downstream distance of $160 \mathrm{~km}$. The shapes and ranges of the histograms change systematically with distance downstream. At line A the histogram is sharply peaked and over $50 \%$ of the observations occur within a narrow $10-\mathrm{km}$ range. At this westernmost section the well-defined northern limit to the Gulf Stream's movements corresponds closely to the 1000 - to $2000-\mathrm{m}$ isobaths. Southward displacements are not as sharply limited, and the Gulf Stream can shift as far as $50 \mathrm{~km}$ offshore. At lines $B$ and $C$ the histograms remain peaked but become progressively more symmetric, and the Gulf Stream shifts through a wider range. Farther downstream at line $D$, the distribution is uniform, and the Gulf Stream is found with equal probability throughout a $145-\mathrm{km}$ excursion range. Thus our study area ranges from a region where the Gull Stream sometimes brushes the continental margin to a region where it flows as a free jet.

To examine long-period seasonal and interannual shifts in the Gulf Stream position, monthly averages of the path displacements near $73^{\circ} \mathrm{W}$ were determined from a 3-year time series at line B. The monthly averages, as well as the yearly mean positions, vary between consecutive years by as much as the seasonal peak-to-peak range itself. There is, however, a consistent trend between all deployments for the Gulf Stream to flow along southerly paths in the winter/spring and northerly paths in the summer/fall. Averaging over 6-month-long periods, the more southerly (northerly) positions are found in the winter/spring (summer/fall) and correspond to times of maximum (minimum) transports reported by Halkin and Rossby [1985] for the same location.

For all lines the spectra of the lateral displacement time series are red and show no preferred or excluded bands of energy from periods of 4 days out to as long as 8 months. We found no differences in the spectral properties when spring/ summer and fall/winter portions of the 36-month record were separately ensemble-averaged. This is different from the region upstream of Cape Hatteras where Brooks and Bane [1983] found significant seasonal differences in the variance spectra of velocity components associated with meanders. The coherences of the path displacements at different pairs of lines were high for all meander periodicities greater than $\mathbf{4}$ days at downstream separations of 50-70 km. At distances greater than 100 $\mathrm{km}$, however, coherences are significant only for a narrow period band at 7-8 days and for periodicities greater than 20 days.

From this extensive set of measurements we have been able to refine and extend the observed dispersion relationship for the growth and propagation of Gulf Stream meanders. Downstream propagation rates decrease smoothly from about $\mathbf{4 5}$ $\mathrm{km} \mathrm{d}^{-1}$ for meanders with periods and wavelengths (4 days, $180 \mathrm{~km})$ to about $14 \mathrm{~km} \mathrm{~d}^{-1}$ for the (33 days, $\left.500 \mathrm{~km}\right)$ meanders. Rapid growth rates occur in two period bands, one for $T>10$ days, $\lambda \approx 300-500 \mathrm{~km}$, and the other for $T \approx 4-5$ days, $\lambda \approx 200 \mathrm{~km}$. In both bands the $e$-fold growth scales are comparable to the periods and wavelengths of the meanders themselves.

\section{APPENDIX}

\section{A1. Seasonal Correction of Acoustic Travel Time}

Since the surface layers $(<200 \mathrm{~m})$ undergo seasonal warming and cooling, the acoustic travel times can change seasonally by $1-1.5 \mathrm{~ms}$ without a lateral shift in the Gulf Stream's position. This seasonal change in travel time has the following effect on the inferred thermocline depth. If we use the simple linear relationship between depth of the thermocline and $\tau$, the $Z_{15}$ values could have a resulting bias error of as much as 20-30 m. For the range in slope of the main thermocline across the Gulf Stream $\left(10^{-3}\right.$ to $\left.10^{-2}\right)$, this could introduce an error of 3-30 km in the estimated position of the Gulf Stream, depending on the proximity of the IES to the north wall.

Our method to minimize this error is as follows. In order to remove the average variation in $\tau$ due to the development of the seasonal thermocline, we calculated the average travel time, $\tau_{200}$, of the upper $200 \mathrm{~m}$ of the water column for each month. To obtain these monthly values of $\tau_{200}$, we first averaged 15 cross-stream sections taken from Iselin [1940], obtaining the average seasonal progression of the hydrography of the upper $200 \mathrm{~m}$ for this region. Figure Ala illustrates the resulting average seasonal temperature cycle. From these data, sound speed profiles were determined and acoustic travel times were integrated. $\tau_{200}$ (Figure A1b) was found to vary by as much as $1.4 \mathrm{~ms}$ with the maximum occurring in March and the minimum in October. A similar range was obtained from the hydrographic data of Schroeder and Stommel [1969] off Bermuda. The relative differences of these monthly averages from the March value were then determined and connected by straight line segments, defining the annual curve, $\Delta \tau$, shown in Figure A1c. This $\Delta \tau$ is subtracted from the measured $\tau$ values to remove the average seasonal variation arising from the upper $200 \mathrm{~m}$. Subsequently, $Z_{15}$ values were calculated from the seasonally corrected $\tau$ values. Although the seasonal variations for any one deployment period may differ slightly from the average curve, the residual error in estimating $\tau$ is probably less than $0.5 \mathrm{~ms}$. The corresponding offset in $Z_{15}$ would be less than $10 \mathrm{~m}$, and the bias in the Gulf Stream position less than $10 \mathrm{~km}$.

\section{A2. Cosine Correction of Gulf Stream Position}

WJ82 discussed the technique of determining the Gulf Stream position from IES measurements. For each $Z_{15}$ measured along a cross section, the mean normal profile $Z_{15}(X$ $\left.-X_{0}\right)$ is used to determine the Gulf Stream north wall position $X_{0}$. A weighted average of $X_{0}$ values is used from two or three IESs along a section. WJ82 showed that the weighted average technique inherently compensates for oblique cross- 

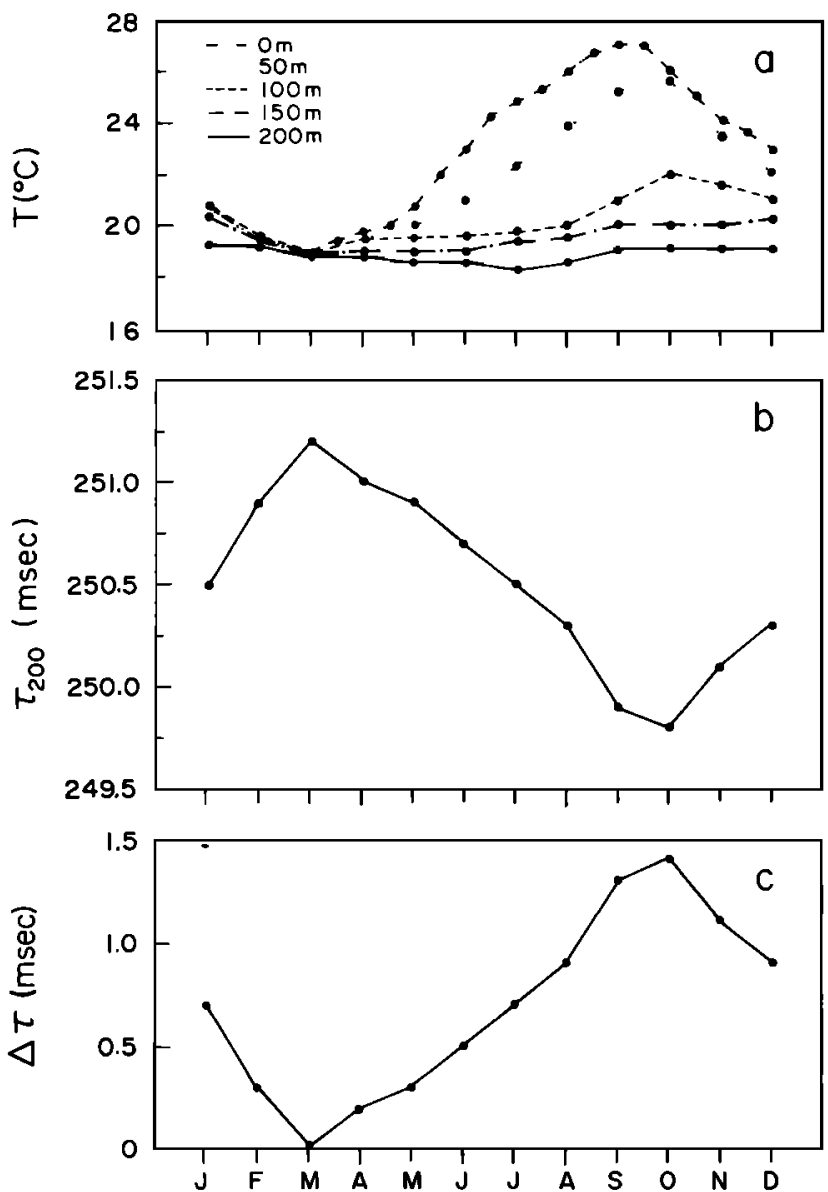

Fig. A1. (a) Plot of temperature versus month for several depth layers in the upper $200 \mathrm{~m}$, averaged from Iselin's [1940] hydrographic sections. (b) The corresponding $\tau_{200}$ integrated for the upper $200 \mathrm{~m}$ plotted versus month. (c) Average annual cycle of $\Delta \tau$, which was used to correct the measured $\tau$ values.

ings of the Gulf Stream quite well when two or more instruments are used on a section, as long as the Gull Stream passes through the section between the IES sites. They pointed out that only when the Gulf Stream axis is more than $20 \mathrm{~km}$ outside the array boundaries would errors arise that would be comparable to those created by variability in the cross-stream structure. When only one instrument is used along a section, such as line A during the 1980-1981 deployment period, these errors could potentially occur much of the time. In such cases the Gulf Stream displacement would be underestimated by a factor $\cos \theta$, where $\Theta$ is the angle between the stream axis and the normal to the section. In order to minimize the errors that would result under these circumstances, we augmented their method to include a cosine correction of the estimated position along cross-stream sections for which the axis is outside the array and which the Gulf Stream crosses obliquely.

The angle of the Gulf Stream path through the array area was calculated from the set of north wall positions along each section. $A(\cos \Theta)^{-1}$ stretch factor was applied to these original position estimates whenever the Gulf Stream crossed a section to the north (south) of the northernmost (southernmost) IES or when a single instrument was used along a crossstream section. At line A, where the meander amplitudes were small, the location of the north wall was adjusted by less than $1 \mathrm{~km}$. On the remaining sections, there was one exceptional case for about 4 days at line $C$ in which the cosine stretching was about $20 \mathrm{~km}$ and the correction on line $B$ was about 3 km. During that time period the Gulf Stream path was complicated by both a shingle and a warm-core ring, making it difficult to assess the accuracy of the correction from the available satellite imagery. Usually, along the remaining sections (B-E), the corrections were smaller than $2 \mathrm{~km}$.

Acknowledgments. It is a pleasure to acknowledge the instrument development and careful preparation done by Gerry Chaplin and Mike Mulroney on the inverted echo sounders used in this work. We would like to thank Captain Jack Tate and the crew of the $R / V$ Endeavor for their aid in the field operations on the many deployment and recovery cruises. We thank Julie Rahn for careful editorial assistance. This work has been supported by the National Science Foundation under grants OCE 79-21029 and OCE 82-01222.

\section{REFERENCES}

Bane, J. M., Jr., and D. A. Brooks, Gulf Stream meanders along the continental margin from the Florida Straits to Cape Hatteras, Geophys. Res. Lett., 6(4), 280-282, 1979.

Bane, J. M., Jr., D. A. Brooks, and K. R. Lorenson, Synoptic observations of the three-dimensional structure, propagation, and evolution of Gulf Stream meanders along the Carolina continental margin, J. Geophys. Res., 86, 6411-6425, 1981.

Blaha, J. P., Fluctuations of monthly sea level as related to the intensity of the Gulf Stream from Key West to Norfolk, J. Geophys. Res., 89, 8033-8042, 1984.

Brooks, D. A., and J. M. Bane, Jr., Gulf Stream fluctuations and meanders over the Onslow Bay upper continental slope, J. Phys. Oceanogr., 11, 247-255, 1981.

Brooks, D. A., and J. M. Bane, Jr., Gulf Stream meanders off North Carolina during winter and summer 1979, J. Geophys. Res., 88, 4633-4650, 1983.

Chaplin, G., and D. R. Watts, Inverted echo sounder development, in Oceans '84 Proceedings, vol. 1, pp. 249-253, IEEE, New York, 1984.

Fuglister, F. C., Annual variations in current speeds in the Gulf Stream system, J. Mar. Res., 10, 119-127, 1951.

Fuglister, F. C., Cyclonic rings formed by the Gulf Stream 1965-66, Studies in Physical Oceanography: A Tribute to Georg Wüst on His 80th Birthday, vol. 1, edited by A. L. Gordon, pp. 137-168, Gordon and Breach, New York, 1972.

Hachey, H. B., Temporary migrations of Gulf Stream water on the Atlantic seaboard, J. Fish. Res. Board Can., 4(5), 339-348, 1939.

Halkin, D., and H. T. Rossby, The structure and transport of the Gulf Stream at $73^{\circ} \mathrm{W}$, J. Phys. Oceanogr., 15, 1439-1452, 1985.

Halliwell, G. R., and C. N. K. Mooers, Meanders of the Gulf Stream downstream from Cape Hatteras 1975-1978, J. Phys. Oceanogr., 13, $1275-1292,1983$.

Hansen, D. V., Gulf Stream meanders between Cape Hatteras and the Grand Banks, Deep Sea Res., 17, 495-511, 1970.

Iselin, C. O., Preliminary report on long-period variations in the transport of the Gulf Stream, Pap. Phys. Oceanogr. Meteorol., 8(1), $1-40,1940$.

Legeckis, R. V., Satellite observations of the influence of bottom topography on the seaward deflection of the Gulf Stream off Charleston, S.C., J. Phys. Oceanogr., 9, 483-497, 1979.

Montgomery, R. B., Fluctuations in monthly sea level on eastern U.S. coast as related to dynamics of western North Atlantic Ocean, $J$. Mar. Res., 1, 165-185, 1938.

Niiler, P. P., and A. R. Robinson, The theory of free inertial jets, II, A numerical experiment for path of the Gulf Stream, Tellus, 19, 601$619,1967$.

Robinson, A. R., J. R. Luyten, and F. C. Fuglister, Transient Gulf Stream meandering, I, An observational experiment, J. Phys. Oceanogr., 4, 237-255, 1974.

Schroeder, E., and H. Stommel, How representative is the series of Panulirus stations of monthly mean conditions off Bermuda?, Prog. Oceanogr., 5, 31-40, 1969.

Veronis, G., Dynamics of large-scale ocean circulation, in Evolution of Physical Oceanography, edited by B. A. Warren and C. Wunsch, pp. 140-184, MIT press, Cambridge, Mass., 1981.

Watts, D. R., Gulf Stream variability, in Eddies in Marine Science, edited by A. Robinson, pp. 114-144, Springer-Verlag, New York, 1983. 
Watts, D. R., and W. E. Johns, Gulf Stream meanders: Observations on propagation and growth, J. Geophys. Res., 87, 9467-9476, 1982.

Watts, D. R., and D. B. Olson, Gulf Stream ring coalescence with the Gulf Stream off Cape Hatteras, Science, 202, 971-972, 1978.

Watts, D. R., and H. T. Rossby, Measuring dynamic heights with inverted echo sounders: results from MODE, J. Phys. Oceanogr., 7 , 345-358, 1977.

Worthington, L. V., The causes of North Atlantic circulation, in On the North Atlantic Circulation, pp. 102-106, Johns Hopkins University Press, Baltimore, Md., 1976.

K. L. Tracey and D. R. Watts, Graduate School of Oceanography, University of Rhode Island, Narragansett, RI 02882.

(Received June 26, 1985; accepted July 23, 1985. 